\section{Experimentando las modernidades latino- americanas: Estrategias melodramáticas en los filmes La vendedora de rosas y Pizza, birra, faso}

Experiencing Latin American modernities: Melodramatic strategies in the films $\mathrm{La}$ vendedora de rosas and Pizza, birra, faso

\section{Claudio Salinas-Muñoz ${ }^{*}$}

Hans StANGe-Marcus**

\section{Resumen}

El artículo que proponemos intenta actualizar la noción de lo melodramático como matriz

Instituto de la Comunicación e Imagen, Universidad de Chile, Santiago, Chile. Correo electrónico: claudiorsm@yahoo.com

** Instituto de la Comunicación e Imagen, Universidad de Chile, Santiago, Chile. Correo electrónico: hstangemarcus@yahoo.es cultural en dos filmes latinoamericanos contemporáneos: Pizza, birra, faso (Argentina 1997) y La vendedora de rosas (Colombia 1998). Estas dos películas, inscritas en los llamados "nuevos realismos latinoamericanos" de fines del siglo XX, pueden ser concebidas, también, como dos estrategias audiovisuales que, por medio de las formas melodramáticas, construyen discursos que nos indican, refieren y problematizan distintas estrategias con que los sujetos construyen sus identidades y experimentan las distintas modernidades en Latinoamérica, en contextos de capitalismos avanzados y transnacionales.

Palabras clave: cine latinoamericano, modernidad, experiencia, melodrama, La vendedora de rosas, Pizza, birra, faso.

\section{Abstract}

This article aims to update the notion of "melodramatic" as cultural base of two contemporary Latin American films: Pizza, birra, faso [Pizza, beer, fag] (Argentina 1997) and La vendedora de rosas [The roses seller girl] (Colombia 1998). These two films, framed in the so-called "new Latin American realism" can be conceived as two audiovisual strategies that construct, through melodramatic forms, several discourses that indicate, refer, and problematize different ways through which individuals construct their identities and experience the different modernities in Latin America, in the context of late transnational capitalism.

Key words: Latin American cinema, modernity, experience, melodrama, La vendedora de rosas, Pizza, birra, faso. 
Villas miserias, estaciones de trenes que ya no avanzan, delincuencia juvenil, filas de desempleados, inmigrantes hacinados en conventillos desvencijados. Las imágenes nos ubican en el extremo más degradado del mito de la juventud gris, donde los jóvenes aparecen como el resultado y estandarte de los peores males, 'el emergente' violento, el sector más afectado por la crisis, en fin, 'la desgracia y resaca de la sociedad'. Robar y matar, vender drogas o consumirlas. En el mejor de los casos: no hacer nada y vagar.

(Meschengieser y Lisica 2004: 6).

\section{Introducción}

El siempre complejo término "modernidad" puede ser comprendido, al decir de Brunner (2002), en al menos cuatro sentidos diferentes: como periodo histórico, como estructura institucional, como discurso y proyecto civilizatorio, y como experiencia vital. En este mismo sentido, Brunner, citando a Jesús Martín Barbero en su célebre texto De los medios a las mediaciones, señala que las versiones latinoamericanas de la modernidad, observadas desde ciertos dispositivos de mediación como el mercado, la ciudad, la escuela y sobre todo los llamados medios de comunicación de masas, dan cuenta de una "experiencia de heterogeneidad cultural" (2001: 253), que también es indicada por otros autores (Herlinghaus 2000; Ortiz 2000).

Vastos sectores de nuestras sociedades accederían a las diferentes experiencias de la modernidad a través de los medios de comunicación, en especial por el cine que produce, como buen artificio, la ilusión de realidad. Eduardo Santa Cruz y Luis Santa Cruz (2005) proponen que el trabajo de la industria cultural sería cotidianizar la modernidad, dar sentido a la experiencia común de vivir la vida. $Y$ uno de los principales modos de dar sentido a esta experiencia y narrarla es por medio de lo que Peter Brooks (1976) llamó imaginación melodramática.

Lo melodramático hace ingresar narrativamente a nuestras sociedades en la modernidad periférica. Lo melodramático hace comparecer a nuestras naciones ante unas modernidades que se nos revelan sentimentalmente, afectivamente, por medio de historias de amor y desencuentros, engaños y traiciones, pasiones y excesos de todo tipo. A través de la representación de tragedias familiares, redenciones individuales, gestas amorosas y romances furtivos, lo melodramático se transforma en una herramienta para aprender a valorar, situar y comprender el sistema de clases sociales latinoamericano, los procesos de migración del campo a la ciudad, y la manera en que conviven, en nuestro continente, las promesas de progreso con las certezas de la fatalidad. Lo melodramático se despliega como pura experiencia cotidiana en un teatro bien particular: la ciudad latinoamericana (Salinas 2010). Lo melodramático, históricamente, ha tenido lugar en distintos soportes, reconvertido en variados géneros, desde el folletín de comienzos del siglo XIX hasta las películas hiperrealistas de fines del siglo $X X$ y comienzos de la centuria en curso (Cfr. Sarlo 2000). Lo melodramático, en tanto estrategia de narración -como una manera de contar-nos-, movilizará un conjunto de experiencias hechas de una materialidad particular: las escenas de la vida cotidiana, territorio en el que habita el sentido común de una sociedad.

En este trabajo, no comprendemos lo melodramático nada más como un género, 
tal como hacen muchos de los autores (Cfr. Fuenzalida, Corro y Mujica 2009), sino como una estructura narrativa que no se define a partir de la presencia de marcas convencionales, estereotipos característicos o marcos esencialistas, aunque algo de todo esto esté siempre presente (Salinas 2010). Uno de los autores que ha tratado de entender las estructuras melodramáticas, Hermann Herlinghaus, prefiere concebir el melodrama "no tanto como tema, conjunto de temas o género, sino como una matriz de la imaginación teatral y narrativa que ayuda a producir sentido en medio de las experiencias cotidianas de los individuos y grupos sociales diversos" (2002: 23, cursiva nuestra). Jesús Martín Barbero (2004) lo entiende también como una matriz cultural.

Esta concepción de lo melodramático como estructura narrativa, y no sólo como género, difiere de las concepciones más clásicas sobre el melodrama, que lo reconocen a partir de una serie de reglas y marcas discursivas. El "género melodramático" es el que se aprecia de manera más nítida en cintas populares de México y Argentina durante las décadas de 40 al 60, así como en las telenovelas latinoamericanas, sobre todo en sus "modelos" narrativos venezolano y brasileño (Santa Cruz 2003). La estructura melodramática, en cambio, referiría a una clave de interpretación que puede articular diversos géneros, arquetipos y estereotipos. Por esta razón, lo melodramático ya no se limitará a la representación del sentimiento amoroso sino que extenderá su relato a otros registros sentimentales. De la misma manera, el foco de las acciones narrativas ya no estará centrado en el campo de la vida privada y el espacio íntimo, sino que accederá a otras dimensiones en las que el registro sentimental emerge y empapa lo público, lo político, lo histórico, etc. ${ }^{1}$.

De acuerdo con Martín Barbero y Muñoz (1992), la estructura melodramática articula cuatro sentimientos básicos: el miedo (o los miedos), el entusiasmo, la lástima y la risa. Estos sentimientos se corresponden, a su vez, con cuatro tipos de situaciones o vivencias: sensaciones terribles, excitantes, tiernas y burlescas. Tanto los sentimientos como las sensaciones son personificadas por cuatro tipos de personajes: el traidor, el justiciero, la víctima y el bobo. Y, al entremezclarse, se presentan estructuralmente en cuatro géneros predilectos: la novela negra, la epopeya, la tragedia y la comedia.

Entonces, si admitimos en la estructura melodramática una fértil provincia para comprender las experiencias de la modernidad, ciertos filmes contemporáneos, en los cuales el problema social y las actuales condiciones de vida degradada en las metrópolis latinoamericanas son narrados a partir de estructuras melodramáticas, pueden convertirse en singulares y privilegiados objetos para estudiar el estado actual de nuestras experiencias de lo moderno. Nos referiremos, en este artículo en particular, a dos de estos filmes: Pizza, birra, faso (Adrián Caetano y Bruno Stagnaro, Argentina, 1998) y La vendedora de rosas (Víctor Gaviria, Colombia, 1998).

Estas cintas son usualmente vinculadas con las corrientes de los nuevos realismos

En consonancia, diversos autores vienen señalando la crisis de ciertas categorías modernas que permitían delimitar los espacios de representación, entre los que nos interesan, particularmente, las difuminaciones de lo público y lo privado, así como la separación de razón y emoción. Ver Bauman (1999) y Lipovetsky (1986). 
latinoamericanos (Cfr. León 2005; Aguilar 2006), ya sea que se comprendan como "realismos sucios", "cines de la marginalidad" o cualquier otra denominación. También es habitual que se reconozca, como su tema central, la profunda crisis social y política a la que arrastran las nuevas economías neoliberales a los amplios sectores de los postergados de la ciudad periférica. Nada de esto queremos poner en cuestión, pues nuestra pregunta no es por el objeto de las representaciones de estos filmes, sino por sus modos melodramáticos de narración. De cierta forma, lo que queremos indicar es que el individuo no experimenta la "modernidad" en abstracto y como categoría conceptual, sino como vivencia cotidiana; el individuo experimenta "su" modernidad, en primer término, como crisis familiar además de epocal, como dolor personal además de colectivo, como hambre, como frustración, como calle. Los filmes de Caetano-Stagnaro y Gaviria no quieren explicarnos las razones de la crisis, ni denunciar a sus culpables: su propósito es comprender el modo en que las fatales modernidades latinoamericanas dejan sus marcas en el cuerpo y el corazón de los habitantes invisibles de la ciudad.

Algunos de los recursos de estos filmes se emparentan directamente con aquellos utilizados por el neorrealismo italiano y por los nuevos cines latinoamericanos de hace medio siglo: actores no profesionales, uso de la cámara en mano, preeminencia del sonido directo, filmaciones en entornos reales escamoteando la filmación en estudio, producción de bajo presupuesto, etc. Esta situación motiva, evidentemente, y no de modo desacertado o involuntario, a emparentar estos filmes con la tradición cinematográfica latinoamericana, así como a leer en ellos un sustrato político. Tampoco vamos a desmentir esto, sino a enfatizar que ese sustrato $y$ ese realismo se construyen a partir de una estructura melodramática que está en la base de otras formas genéricas utilizadas por estos realizadores como el western, la comedia negra, el road movie, entre otros (Cfr. Schwarzböck 2009; Aguilar 2008; Ruffinelli y Gaviria 2004).

Estas películas no presentan, por tanto, discursos abstractos: no son experiencias de "subjetividades" o "identidades" respecto de lo moderno, sino que son, fundamentalmente, estrategias de individuos concretos respecto de sus modernidades definidas en un tiempo y un espacio precisos: las ciudades de Buenos Aires y Medellín, en torno al año 1998. Las películas no constituyen ejemplos ni tipos de categorías sociales o estéticas respecto de las cuales se quisiera construir un discurso, constituyen casos en los cuales las categorías (marginalidad, pobreza, delincuencia, etc.) sirven para explicar y movilizar experiencias específicas concebidas melodramáticamente. No son, por ende, como en los años 60, representaciones sobre el orden social moderno y su devenir histórico, sino que son testimonios del conflicto entre los individuos y sus vivencias en las urbes latinoamericanas actuales. Estos filmes son expresiones de lo particular, no de lo universal; experiencias de modernidades y no representaciones de la modernidad.

Este artículo intentará demostrar que las películas señaladas emplean estrategias melodramáticas para representar unos aspectos específicos de las modernidades latinoamericanas: la degradación del individuo en los regímenes neoliberales contemporáneos que generan, en torno de las grandes ciudades de la región, cordones de miseria. 
Lo melodramático supone que las vías de representación en estos filmes no emplean primordialmente estrategias discursivas políticas, documentales o argumentales, sino que subordinan dichas representaciones a la construcción de una experiencia sentimental que dota de sentido a la vivencia de los sujetos marginales representados. Para ello, se describen tres dimensiones en la representación de los filmes: la caracterización de los sentimientos a partir de los cuales los sujetos comprenden su relación con el entorno, los medios que la ciudad ofrece para construir la experiencia social como experiencia afectiva, $y$, por último, las estrategias afectivas con las cuales se representa, en el ámbito del individuo, una valoración crítico-política de su experiencia de las modernidades latinoamericanas.

\section{La oposición entre el individuo y el mundo}

El Cordobés, protagonista de Pizza, birra, faso, junto a sus compañeros de fechorías, son delincuentes de poca monta. Viven en un Buenos Aires que los rechaza como ciudadanos. Dependen de un taxista, tan delincuente como ellos, para poder realizar sus atracos. El Cordobés tiene una novia, embarazada, que le apremia por buscar mejores expectativas y abandonar la vida criminal, pero su propia ineptitud, la falta de oportunidades y el entorno social que le rodea, le impiden progresar. El mundo parece estar contra el Cordobés y su pandilla, frente a lo cual la única salida posible pareciera ser un golpe de suerte: un gran asalto que les dé la "guita" suficiente para abandonar la ciudad y comenzar de nuevo. Por supuesto, todo irá de mal en peor, como no podría ser de otro modo.
La trama central del filme nos muestra la situación fundamental de un individuo que se enfrenta al conjunto de la sociedad. Este antihéroe, sin embargo, no es un rebelde ni un justiciero ni un revolucionario, sino una víctima de su propia desazón. El Cordobés no está provisto de las herramientas intelectuales que le permitan formular su predicamento en términos discursivos, pero intuye y siente claramente cuál es el nudo de su situación: es un desplazado, un marginado, un perdedor, un resto. Se encuentra permanentemente dominado por la rabia y la frustración, de las que deriva su conducta errática, violenta y, a veces, tragicómica. La pretensión del "golpe de suerte" está fuera de los parámetros del modelo burgués de desarrollo por medio del emprendimiento o del trabajo, tan difundido por las elites y los gobiernos latinoamericanos. El Cordobés representa un tipo de juventud marginal y profundamente malograda que se opone al ideal burgués de juventud, como señalan Meschengieser y Lisica:

sostenemos que aquel joven 'tradicional' que amalgamaba las expectativas colectivas de y para la juventud -sea rebelde, soñador, cuestionadortiende a desaparecer de las pantallas. $Y$ es reemplazado, NCA [Nuevo Cine Argentino] mediante, por el joven indolente de clase media (corriente slacker) o el marginado sin retorno, de clase baja (corriente del realismo social) (2004: 1).

De acuerdo a los tipos propuestos por Martín Barbero y Muñoz (1992), el Cordobés representa un tipo intermedio entre la víctima y el bobo, movilizando nuestros sentimientos de lástima y ridículo. La secuencia del golpe final a una discoteca, puntualizada con la disonante música de fondo de una cumbia villera, es claramente la muestra de un destino frustrado por el azar en unos mundos sin salida, excluidos 
del consumo, marginados del capital cultural y en los escalafones más bajos del hampa (León 2005).

Todo el coro de personajes de la ciudad (los policías, los médicos y enfermeros, los cesantes, los transeúntes) se constituye en opositor al Cordobés y su grupo, en obstáculos a lo largo de su camino singular de mejoramiento. No son, moralmente hablando, mejores que ellos, menos corruptos o más exitosos. El coro del filme es una muestra de un mundo tan caído como el propio Cordobés, en el que el orden jurídico moderno está ausente o trastocado, el Estado casi no aparece y cualquier otro tipo de signo institucional está capturado en un esquema de relaciones personales callejeras, afectivas o de interés. El Cordobés no lucha contra el Estado ni contra un partido político o una clase social; no convoca, tampoco, a una movilización de clase -aunque tenga plena conciencia de su lugar en el sistema de clases sociales-. La redención, si la hay, obra por la vía individual.

De un modo distinto al del Cordobés, Mónica, la protagonista de La vendedora de rosas, siente también la oposición del mundo. Arrojada a la calle tras la muerte de su abuela, vive junto a otras niñas como ella (huérfanas, delincuentes o que por algún motivo han abandonado su hogar) en una pensión, subsistiendo mediante la venta de rosas a los clientes de los bares nocturnos de Medellín. Sus amigos, y ella misma, se mantienen por las noches a punta de aguardiente y sacol, un alucinógeno inhalante que permite soportar el frío y el hambre, las extenuantes jornadas callejeras, a la vez que les posibilita abandonar momentáneamente la monótona y trágica realidad en que se desenvuelven. Mónica no siente al mundo como una dificultad o una traba, pero lo padece como una carga. No quiere estar en él, sino junto a su abuela fallecida, a la que ve, transfigurada como la Virgen María, en medio de sus alucinaciones. El mundo sólo ofrece para Mónica los medios de subsistencia y algo parecido a un continuo pesar: una de sus amigas de la calle le arrebata a su novio (un adolescente consumido por el sacol), otra amiga se transforma en una preocupación al abandonar la casa en la que vivía con su madre y el conviviente de ésta, y un pistolero de gatillo fácil y cabeza sulfurada por el alcohol y la cocaína, el Zarco, aspirante a soldado del narcotráfico, la persigue para arrebatarle un reloj que Mónica ha recibido como obsequio. Las acciones desarrollan trayectorias no lineales en el filme y los actos dramáticos se presentan siempre a punto de desbaratarse, como provisorios o azarosos. La principal marca de identidad de Mónica y sus amigos es, a ojos del espectador, la jerga callejera de Medellín (el parlache), junto con la apabullante naturalidad con que las cosas más terribles parecen suceder, sin que nadie se espante por ello. De alguna manera, como señalan Ruffinelli y Gaviria (2004), Mónica y sus amigos son los "desechables" de la ciudad, la escoria de la que nadie quiere hacerse cargo, pero que inevitablemente pulula entre los "ciudadanos" de la Medellín legal².

Mónica se siente completamente expulsada de este mundo. Sabe sobrevivir en él, al igual que casi todas las demás niñas de la calle, pero el ansia de un afecto como el de su abuela,

\footnotetext{
La estrategia "realista" de estos filmes adquiere filos dramáticos. Es particularmente conocido el caso de La vendedora de rosas, para cuya realización Gaviria reclutó a auténticos "desechables". Lady Tabares, la niña que interpretó a Mónica, posteriormente sería encarcelada (salió recién en libertad en el año 2014), y Giovanni Quiroz, intérprete de Zarco, fue asesinado a tiros de modo similar al que exhibe la cinta.
} 
la fragilidad y la inseguridad de su existencia (se trata, al fin y al cabo, de una niña), marcan profundamente su estado emocional. Mónica está siempre un poco triste, siempre se ve sola, aun cuando a su alrededor esté su novio, sus amigas y la multitud de los desplazados de "Medallo". Su personaje encarna el tipo de la víctima, de acuerdo a la caracterización de Martín Barbero y Muñoz (1992), y en no pocos pasajes produce en el lector algo parecido al estupor. La actitud fundamental de Mónica es la tendencia a la evasión, que aquí no reviste cualidades de mala fe o falsa conciencia (en el sentido marxista del término), sino que constituye una respuesta sentimental frente a un entorno en el cual ella no encaja ni desea encajar. Evadirse es una táctica de sobrevivencia, un modo de postergar la fatalidad (que, ineludible, llegará finalmente de manos del Zarco).

La decisión, voluntaria o no, de vivir en la calle, es al mismo tiempo un ejercicio de autodeterminación por parte de Mónica y sus amigas, una forma de afirmación personal y de respuesta a su exclusión. Vivir en la calle es la manera que estas niñas tienen para hacerse cargo de sus propias vidas. Mientras el "golpe de suerte" aparece como la respuesta ante el mundo por parte del Cordobés en Pizza..., la calle es el teatro de realización de la única vida posible de estos "otros", los desechables de Medellín. El mundo social no es, entonces, el opositor de Mónica -como sí lo era para el Cordobés- sino sólo su testigo indiferente. La soledad de Mónica tiene su complemento en la indolencia de la ciudad hacia ella y las demás niñas de la calle: abandonadas por cualquier institución del Estado, así como por organizaciones privadas o por cualquier otro que pudiese hacer algo por ellas, el orden social les permite deambular como espectros, apenas visibles, rápidamente olvidados y siempre anónimos. La única interacción (si se puede hablar así) entre ambos mundos ocurre cuando la Medellín "legal" recuerda que estos desechables pueden ser una amenaza al orden instituido, frente a lo cual se debe recurrir a la violencia. Así, el Zarco, epítome del traidor (según la tipificación de Martín Barbero y Muñoz), vehículo del miedo y de las más bajas pasiones, enajenado por la droga hasta el punto de no distinguir amigos de enemigos, caracteriza a ese "otro amenazante" que la ciudad tanto teme, a los estereotipos del asesino y del delincuente, o bien, simplemente, a la amenaza del desorden sin sentido, transformado en el peor miedo de las democracias contemporáneas (el "terrorista", el "violentista"), conminado a desaparecer tan fugaz y burdamente como ha aparecido.

En otros filmes latinoamericanos con temáticas similares es posible encontrar esta misma estructura fundamental: la de un individuo o individua en conflicto con el mundo y que percibe esa confrontación bajo la forma de un sentimiento. En Rosario tijeras (Emilio Maillé, Colombia, 2005), por ejemplo, la protagonista reserva sus sentimientos amorosos, auténticos y verdaderos en medio del violento mundo de los sicarios. Y en El bonaerense (Pablo Trapero, Argentina, 2002), la relación amorosa de Zapa, el protagonista, con Mabel, su instructora en el cuerpo policial, se ve amenazada cuando él comienza a asimilar e interiorizar la cultura cotidiana de la "bonaerense", la corrupta policía de Buenos Aires, es decir, con la intromisión del mundo exterior en el espacio íntimo.

En casi todos estos filmes, también, el sentimiento de soledad, abandono o frustración 
que está en la base de los padecimientos de los personajes protagónicos es, además, un símbolo de una exclusión que no sólo es económica y social, sino que opera también "en los campos epistemológicos, simbólicos y culturales" (León 2005: 39). El Cordobés y Mónica no sólo deben estar excluidos sino que deben sentirse como tales, para no amenazar los discursos a partir de los cuales la nación y la ciudad construyen la identidad de un "nosotros" moderno.

\section{La ciudad como lugar de las formas melodramáticas}

Entre los discursos cotidianos sobre la marginalidad y la criminalidad urbana emergió con renovadas fuerzas una imagen: la de la ciudad como un lugar contaminado no por los ruidos ni la polución industrial de la modernización periférica, ni por los residuos petroquímicos de los motores que la cruzan, sino por una 'polución humana'.

(Jáuregui y Suárez 2002: 367-368).

El conflicto entre el individuo y la sociedad, desarrollado bajo las formas melodramáticas del miedo, el pesar y la frustración, tal como se muestra en estos filmes, tiene un teatro de acción particular: la metrópolis latinoamericana. Buenos Aires y Medellín tienen papeles protagónicos en ambas cintas y distan de ser meros decorados o locaciones. Tanto Pizza... como La vendedora... son películas eminentemente urbanas, no porque transcurran en la ciudad, sino porque representan un conjunto de relaciones sociales $-\mathrm{y}$, por tanto, sentimentales- que sólo se producen en ese espacio. En efecto, como señala Delgado, lo urbano no es un lugar sino "un estilo de vida marcado por la proliferación de urdimbres relacionadas, deslocalizadas y precarias" (Cit. en Pérez 2008: 175), "más que el espacio en el que transcurren los acontecimientos de una película, es un hilo conductor de la historia, se conforma como el universo imaginario en el cual se desarrolla el relato" (Cit. En Pérez 2008: 176177). Además del crecimiento espectacular, señala Héctor Quiroz,

la ciudad latinoamericana contemporánea se caracteriza por ser el resultado de una doble realidad: por un lado el proyecto oficial, inspirado en la ideología del progreso y basado en la vanguardia tecnológica, y por otra la ciudad construida de manera espontánea por millones de marginados (2001: 6).

Lejos de las imaginaciones sobre la ciudad que proyectan en ella el imperio del progreso y la razón, el orden de lo moderno y la pasión por la ley y la tecnología -para referirnos a un lugar común, digamos, lejos de la "ciudad letrada"las películas de las que hablamos nos presentan una ciudad melodramática, una ciudad que es objeto y canal de los sentimientos de los protagonistas de estos filmes, escenario de su condición de marginalidad, en virtud de la cual se trastocan los espacios de lo público y lo privado, con sus relaciones sociales concomitantes. En la ciudad de los desclasados y los sin hogar, las calles son tanto habitación, baño y cocina, como el lugar en el que se forman las relaciones filiales, ya no según el modelo tradicional de familia, sino de acuerdo a las relaciones afectivas que la vida callejera ofrece. Hermann Herlinghaus, según cita Martín Barbero, reconoce este doble carácter marginal y sentimental de las ciudades del continente:

"Ciudad melodramática" llama $\mathrm{H}$. Herlinghaus al nuevo espacio en el que, frente a las exclusiones socioculturales de la "ciudad letra", adquieren visibilidad cultural y relieve político las narraciones en las que se expresan y constituyen nuevas 
subjetividades e identidades que, como las de la mujer -protagonista tanto ancestral como moderna del melodrama-, apuntan a la transgresión social desde lo emocional convirtiendo "los desafíos del amor en derecho a la felicidad" y a ésta en "problema de justicia" (2004: 32).

Jaime Pena señala elocuentemente cuál es el papel de Buenos Aires en la cinta de Caetano y Stagnaro:

Las primeras imágenes de Pizza, birra, faso causaron una impresión profunda en los espectadores. Se veían imágenes de Buenos Aires de lugares reconocibles como la plaza Constitución o el Obelisco, o de elementos clásicos de la ciudad, como los vendedores ambulantes o los colectivos (...) Sin embargo, los movimientos nerviosos de la cámara, el montaje frenético, el sonido ambiente reforzado por el murmullo de una emisora radial y una música que resultaba nueva para la tradición del cine argentino -la cumbia- decían que se estaba ante el comienzo de un cambio de paradigma. Cuando finaliza el prólogo y la película se enfoca en sus protagonistas, aparece una nueva sorpresa: el lenguaje (2009: 111).

El uso de lugares icónicos de la ciudad, revestidos con la apariencia de lo marginal (la cumbia villera, el lenguaje delincuencial), sitúan en el filme los imaginarios sobre la ciudad dentro de los marcos del "realismo" latinoamericano. La cámara se pasea como testigo de las actividades de la ciudad en la mañana (los bocinazos). La fotografía es austera, sin perderse en planos accesorios y concentrándose en los movimientos y ritmos de la ciudad, plagada de afiches de huelgas que anticipan visualmente la crisis económica argentina de fines de los años 90. En este contexto, las calles de la ciudad pierden tanto su carácter simbólico y monumental, así como su condición de espacio público tradicional, para convertirse en un espacio de relaciones mercantiles -legales o no- en el que son instrumentalizadas casi todas las relaciones humanas. Ciertos lugares comunes como aquel que ve la ciudad como una "jungla de cemento" parecen ser aquí corroborados. Sin embargo, el casi referido es muy importante. En medio de este espacio impersonal, el Cordobés desarrolla toda su vida afectiva. Él, su pareja y sus amigos, comen y duermen, sueñan y se ríen, delinquen e imaginan el futuro, en las calles. Para el Cordobés y su pandilla, la ciudad abierta -las calles y plazas, no sus habitáculos, sus salones o sus recintos cerrados- son el lugar de desarrollo de la vida doméstica. Es en este escenario, por tanto, en el que se construyen las relaciones filiales entre el Cordobés y la novia que lo espera y lo perdona; entre él y Pablo, el amigo que se sacrifica para que "Córdoba" intente huir de la ciudad, cruzando el río de La Plata.

Revestida de este doble carácter, la ciudad es, por un lado, espacio de amenaza y de relaciones impersonales para estos sujetos marginales, al mismo tiempo que, por otro lado, es la condición de posibilidad para la construcción de relaciones afectivas. Jungla y hogar a la vez, Buenos Aires es imprescindible para la formación del sentimiento del protagonista, pues sin sus calles, sin su ajetreo, sin el abarrotamiento de los migrantes en sus márgenes, sin los ostensibles símbolos de la modernidad que lo excluye, el Cordobés no podría dar forma a la frustración con que experimenta su vida cotidiana, ni al anhelo por ese golpe de suerte que cambie por fin su fortuna.

Mónica, la protagonista de La vendedora de rosas, tampoco podría estructurar el sentimiento fundamental de desarraigo que presenta en la película, en otro lugar que no 
fuera Medellín, con su reunión de bullante prosperidad y dolorosa miseria. El punzante aislamiento de Mónica, su sensación de no pertenecer a ningún lugar, se corresponde con la ausencia de un espacio íntimo o doméstico, reemplazado aquí, al igual que en Pizza..., por la sociabilidad de la calle. Las niñas de la calle han devenido en su familia, mientras que los parientes cercanos están ausentes o se han vuelto opositores. "Como una característica particular de estos personajes", dice Pérez, "se encuentra su conocimiento de la calle, que es el lugar que habitan; así conozcamos sus casas y su barrio, la mayor parte del tiempo están en la calle y la recorren como si fuera su casa" (2008: 181). La única relación afectiva familiar, su abuela fallecida, no representa una relación social concreta sino un símbolo de su desarraigo, el significante de su anhelo por abandonar la precariedad de la calle, espacio de trashumancia a la vez que de exilio obligado.

La misma Medellín de Mónica porta esta condición de ajenidad para los espectadores del filme. En los planos de los cafés y bares del centro, contra los edificios residenciales y comerciales del progreso económico, se proyectan en el horizonte los cerros de la ciudad, plagados de los "barrios de inundación", interminables construcciones ligeras, en muchos casos carentes de servicios básicos, en los que Mónica y los suyos deambulan. Ambas ciudades, la próspera y la sucia, Medellín y "Medallo", se entremezclan y conviven, revelando que la condición de Mónica es compartida por un gran grupo de la población, que su sentimiento de exclusión bien puede ser el modo con que muchos de su generación, y de otras, han vivido y sufrido la ciudad. Jáuregui y Suárez contrastan el modo en que la ciudad asigna a sus habitantes distintas posiciones de identidad: "ciudadanos" y "desechables":

Propiamente hablando, el 'desechable' es el opuesto constitutivo de la nacionalidad. En el caso de los 'desechables' resulta fatalmente exacta la proposición según la cual el consumo define identidades. Los 'desechables' son identificados por el ciudadano pleno con los residuos, y consecuentemente ubicados más allá de la mirada, en los confines o 'tugurios' de la representación y el reconocimiento social (2002: 368).

Si el sentimiento (de frustración, de anhelo, de esperanza, de fuga) emerge en estos filmes como la forma preeminente de los individuos para intuir y enfrentar su conflicto con el mundo, la ciudad es el teatro en el cual ese sentimiento se vuelve experiencia concreta: un modo de interactuar con la realidad social y material. La ciudad es, por tanto, la retícula social en la que el sentimiento adquiere su forma melodramática, pues es ella, como marco o como oponente, la que vuelve patente las tensiones de la modernidad que estos sujetos padecen.

\section{El sentimiento melodramático como apertura del mundo externo}

Se ha señalado que la crítica enmarca las dos películas examinadas dentro de las grandes corrientes contemporáneas del "realismo" social latinoamericano, enfatizando dos aspectos temáticos relevantes: en primer lugar, la representación de la exclusión y la marginación de los individuos al interior de las grandes urbes del continente $y$, en segundo término, la existencia de un trasfondo político. Podríamos pensar, de manera provisoria, que estos dos aspectos constituyen las experiencias de lo moderno latinoamericano que los(as) individuos(as) de estos filmes 
elaboran sentimentalmente, y que son, por tanto, representados mediante una estructura narrativa melodramática.

La reactualización de las estructuras melodramáticas -que en su vertiente genérica fueron un modo de representación muy habitual en el cine latinoamericano de comienzos del siglo XX- puede tener relación con la desestimación de las formas más militantes y comprometidas del discurso fílmico político que tuvo su apogeo en las décadas del 60 y 70 (los nuevos cines latinoamericanos). Tanto Gaviria como Caetano-Stagnaro parecen no querer renunciar a una mirada crítica sobre la realidad que reconstruyen en sus películas, al mismo tiempo que desconfían de los procedimientos retóricos y discursivos de la militancia política. Ni Pizza... ni La vendedora... llaman a la revolución, incitan la toma de conciencia, denuncian una clase social particular o enarbolan algún tipo de manifiesto. Sus estéticas no son masivas ni épicas. Sus discursos no apuestan por el compromiso explícito o la monserga partidista, considerados ya formas extemporáneas, anacrónicas y profundamente inadecuadas para la producción eficaz de la representación cinematográfica. Sin embargo, el compromiso con la realidad sigue intacto en estos filmes, y con ello, su sustrato crítico (como lo atestiguan los propios realizadores; ver Ruffinelli y Gaviria 2004; Schwarzböck 2009). La realidad, es decir, las experiencias de lo moderno y sus representaciones, son trabajadas en estas cintas no por el discurso político explícito ni por una poética del compromiso; éstos son reemplazados por la forma melodramática, que ya no coloca en el centro de la trama un conflicto de clases, sino un conflicto afectivo; que ya no problematiza una categoría social (el pueblo, la clase, la nación), sino la fragilidad de un individuo debilitado en medio de un contexto social inhóspito; que ya no apela a la acción política como vía para la transformación de la realidad, sino a una transformación interior en el terreno de los afectos; y que, a pesar de esta reversión hacia el individuo, no constituye un cine desmovilizador y despolitizado, sino, por el contrario, un cine profundamente crítico con el presente (aunque, en cierta forma, pasivo frente a él) $)^{3}$.

Al interior de la trama de los filmes, la forma melodramática ofrece una vía de resolución al conflicto entre el individuo y el mundo construyendo, bajo la modalidad de la ensoñación, una apertura de la experiencia moderna. Para el Cordobés y su pareja, Paty, esta ensoñación es la de la huida. La posibilidad de empezar una vida mejor en Uruguay, junto al hijo que viene, constituye la promesa de redención personal y mejoramiento, el acceso a un "más allá", ni metafísico ni utópico, fuera de los marcos de la cotidianidad opresiva de la gran ciudad. Esto lo señala bien Verardi:

\footnotetext{
El Río de la Plata, por su parte, funciona como el límite detrás del cual se extiende la esperanza de una vida nueva: “¿Sabés qué estaba pensando?”, le dice uno de los jóvenes a su novia, "Que podíamos irnos los dos al Uruguay". "Los tres", corrige ella, haciendo alusión a su embarazo. (...) Del lado de Buenos Aires no parece haber ninguna posibilidad de futuro (2009: 3).
}

\footnotetext{
Probablemente este cine sea el exacto contrapunto de otras corrientes reconocidas como "cines de la intimidad", que reclaman el imperio de lo subjetivo como su espacio de representación aunque, en la práctica, anulan la posibilidad de un discurso subjetivo al carecer de una política representacional que construya en el discurso las relaciones entre sujeto y mundo (véase Póo, Salinas y Stange 2012).
} 
En el caso de La vendedora..., el punzante recuerdo que Mónica tiene de su abuela se convierte en el centro de una ensoñación hacia el pasado: es la memoria del hogar perdido y la añoranza de un tiempo anterior, marcado por la vida familiar y la contención materna, percibido como mejor que el presente degradado por la droga, la violencia y el dinero, lo que conforma la vía por la cual Mónica se abre paso a su conflictiva experiencia del presente. Sin embargo, como esta ensoñación constituye una regresión infantil que se contrapone a la obligada vida adulta, callejera y sexualizada que la niña lleva en Medellín, dicha apertura no ofrece la promesa de una huida o un mejoramiento real (como en el caso del Cordobés) y, por ello, su única resolución posible es que Mónica abandone el mundo de la experiencia con su muerte.

En tanto estructura narrativa, la forma melodramática ofrece la posibilidad de construir un tipo de discursividad crítica que desmitifica las relaciones sociales y las experiencias cotidianas que se originan en los recovecos marginales de las grandes ciudades, revelando la estructura de clases y las relaciones de poder subyacentes en la existencia mundana de estos "marginados" y "desechables", pero no se trata de una operación que remite a un acto de conciencia que, en última instancia, deba transcender al plano de lo colectivo, sino que conduce a los individuos a otro plano, configurado ciertamente desde los afectos, y en el cual la experiencia moderna se presenta bajo las formas de la fatalidad, la destinación y la inexorable injusticia. Estas formas serán movilizadoras para los personajes de los filmes en su relación con el mundo, aunque no entrañen, en último término, la promesa utópica de la transformación del mundo.
En comparación con las películas latinoamericanas de los años 60 , se percibe aquí una especie de crítica "blanda" o "pesimista" (no sólo en estas películas, también en otras como Un oso rojo, también de Caetano, 2002, o El polaquito, de Juan Carlos Desanzo, 2003). En los filmes de los 60 la posibilidad de cambio demanda la construcción de un sujeto consciente y comprometido, un sujeto "histórico" y "político", en cambio, el mundo naturalizado de las películas estudiadas en este artículo sólo deja al sujeto la posibilidad de acción sobre sí mismo, sobre sus afectos o ensoñaciones; un sujeto melodramático. Esta diferencia entre los cines de los años 60 y los presentes, en lo que respecta al tipo de politicidad, es notada también por Jáuregui y Suárez, a propósito del filme de Gaviria:

\begin{abstract}
Algunas de las prácticas del Nuevo Cine Latinoamericano persisten en el trabajo de Gaviria pero, en términos generales, puede decirse que se aleja de muchas de las premisas políticas y de compromiso de éste, y que el 'neorrealismo' de Gaviria corresponde mejor a la fractura que a las propuestas y agendas de liberación y representación popular de los sectores de izquierda de los años 60 y 70 (2002: 372).
\end{abstract}

También en el caso de Pizza..., otros autores han notado que la reticencia a las formas del discurso militante no significa la pérdida de un fondo político en la representación. Meschengieser y Lisica, por ejemplo, señalan que, evitando el manifiesto y la denuncia explícita, Caetano y Stagnaro proponen un viaje en el que se mezclan la precariedad del empleo, la influencia de los medios en la agenda pública, la decadencia del Estado, las privatizaciones, la cultura de la corrupción, la exclusión, el endeudamiento, etc. "En suma, el inventario general de lo que suele denominarse 'menemismo'” (2004: 2). 
Las formas melodramáticas aparecen como medios de expresión y representación de unos individuos cuya experiencia de la modernidad es, paradojalmente, la de estar excluidos de sus beneficios. En una época de crisis política y social, en medio de la bancarrota de una estética movilizadora y comprometida, la forma melodramática ofrece la posibilidad de estructurar unas narraciones y unas convenciones genéricas, usando como base los afectos, y desprendiéndose de conceptuosas explicaciones sobre el "imperialismo cultural", la "lucha de clases" o la "dependencia cultural". En su lugar, se producen complejas formas de representar, en un nuevo horizonte de posibles verosímiles, la anomia, la degradación y la diferencia como modos de vivir y sentir lo moderno.

\section{Conclusión}

\section{Las cintas de Caetano-Stagnaro y Gaviria} representan, mediante estructuras melodramáticas, las experiencias modernas del desarraigo y la exclusión, de la degradación y el mejoramiento, de la crisis y la fatalidad. Estas experiencias son desarrolladas en su dimensión cotidiana y vívida, no como metáforas o alegorías de "grandes relatos" o procesos abstractos. Están enmarcadas en una visión conflictiva, desigual y altamente política de la realidad latinoamericana.

A diferencia de La vendedora... o de cintas como El polaquito (Desanzo, Argentina, 2003) en Pizza... la relación del individuo con la sociedad está marcada por una expectativa de mejoramiento. Esto no supone una representación conservadora: la salida no es la revolución, es cierto, pero igualmente se trata de sujetos que aspiran a la libertad y a la subversión individual del orden. Son sujetos con "bronca": su politicidad está dada por las posibilidades de ingreso y salida del sistema. En la medida en que la esperanza de este mejoramiento está cifrada en el azar -el golpe delictivo-, el filme despliega un conjunto de imaginarios modernos referidos a la autodeterminación, el impulso vital de la voluntad, y la percepción de que estamos en posesión de nuestro propio destino y felicidad, aun contra las fuertes determinaciones sociales. La ciudad de Buenos Aires, por contraposición a estas expectativas de los individuos, aparece como el gran opositor a los anhelos del Cordobés y sus amigos. Es el símbolo de la promesa de modernidad devenida en corrupción, clientelismo e inequidad. Conforma el segundo eje de la relación entre unos individuos modernos marginales luchando por liberarse de una experiencia de lo moderno degradada.

Laexperienciamodernafundamental de Mónica, en cambio, es la del desarraigo y la incomodidad del no-lugar. La pequeña vendedora de rosas no pertenece realmente a la ciudad $\mathrm{y}$, por tanto, existe también fuera de las fuerzas modernizadoras o, más bien, como saldo o desecho de ellas. Como testimonio cotidiano de los costos de la modernización. En contraste con una Medellín emergente, próspera y que supera poco a poco el trauma de la violencia, los niños de la calle experimentan una ciudad amenazante y turbia, un lugar enquistado en el mero presente, sin posibilidades de desarrollo. "Medallo" es, también, el saldo y desecho de la modernización. Esta relación cerrada sólo deja dos alternativas a la experiencia cotidiana: la de asumir de manera afirmativa la condición de rémora, construyendo la cotidianidad bajo los signos visibles de la amenaza, el peligro y la 
sobrevivencia (ser una mujer en cuerpo de niña, ser un adolescente-soldado del narcotráfico, ser en cualquier caso el "enemigo"), o bien, admitir la fatalidad de este proceso y experimentar lo moderno como sacrificio.

En estas películas, y muchas otras de similares corrientes, las relaciones se representan o expresan a partir de oposiciones o dicotomías bien clásicas: amor-deber, individuo-mundo, amor-clase social, individuo-grupo, familiatrabajo, mundo civil-mundo criminal, etc. Son oposiciones que tienen su raíz en las distintas fuentes del romanticismo y que adquieren carácter de fórmula en estas estructuras melodramáticas contemporáneas. Son estas oposiciones las formas melodramáticas con las que se representaría la experiencia presente que los sujetos marginales tienen de lo moderno en América Latina.

\section{Bibliografía}

Aguilar, G. 2008. Estudio crítico sobre el Bonaerense. Entrevista Pablo Trapero. Buenos Aires: Picnic. 2006. Otros mundos: Un ensayo sobre el nuevo cine argentino. Buenos Aires: Santiago Arcos.

Bauman, Z. 1999. En busca de la política. Buenos Aires: FCE.

Brooks, P. 1976. The melodramatic imagination. Balzac, Henry James, Melodrama and the Mode of Excess. New Haven-London: Yale University Press.

Brunner, J. 2002. "Modernidad". Términos críticos de sociología de la cultura. Altamirano, C. (Ed.). Buenos Aires: Paidós. 173-180.

2001. "Modernidad: Centro y periferia". Revista del Centro de Estudios Públicos 83: 241-263.

Fuenzalida, V., Corro, P. y Mujica, C. (Eds.). 2009. Melodrama, subjetividad e historia en el cine y la televisión chilenos de los 90. Santiago: Pontificia Universidad Católica de Chile.

Herlinghaus, H. 2002. "La imaginación melodramática. Rasgos intermediales y heterogéneos de una categoría precaria". Narraciones anacrónicas de la modernidad. Melodrama e intermedialidad en América Latina. Herlinghaus, H. (Ed.). Santiago: Cuarto Propio. 21-59. 2000. "Comprender la modernidad heterogénea: Recolocar la crítica dentro de la crítica". Revista Iberoamericana 66 (193): 771-784.

Jáuregui, C. y Suárez, J. 2002. "Profilaxis, traducción y ética: La humanidad 'desechable' en 'Rodrigo D, no futuro', 'La vendedora de rosas' y 'La virgen de los sicarios'". Revista Iberoamericana 68 (199): 367-392.

León, C. 2005. El cine de la marginalidad. Realismo sucio y violencia urbana. Quito: Abya-Yala.
Lipovetsky, G. 1986. La era del vacío. Barcelona: Anagrama.

Martín Barbero, J. 2004. "Narraciones sociales y mediación intercultural. El trabajo intermediador de Hermann Herlinghaus". Nómadas 20: 26-35.

y Muñoz, S. 1992. Televisión y melodrama. Bogotá: Tercer Mundo.

Meschengieser, S. y Lisica, F. 2004. "Apuntes sobre la marginalidad y la apatía: Los jóvenes en el cine argentino de los '90". Revista Chilena de Antropología Visual 4. En línea, disponible en: http://www.antropologiavisual.cl/ imagenes4/imprimir/meschengieser.pdf (visitado en junio de 2013).

Ortiz, R. 2000. Modernidad y espacio. Benjamin en París. Bogotá: Norma.

Pena, J. 2009. Historias extraordinarias <<lsrael Adrían Caetano/Adrián Israel Caetano>>. Buenos Aires: T y B.

Pérez, L. 2008. "La representación de lo urbano en La estrategia del caracol y La vendedora de rosas". Anagrama 6 (12): 173-186.

Póo, X., Salinas C. y Stange, H. 2012. "Políticas de la subjetividad en el 'novísimo' cine chileno". Comunicación y Medios 26: 5-11.

Quiroz, H. 2001. El malestar por la ciudad contemporánea a través del cine. En línea, disponible en: http://www.art-mirall.org/proyecto/quiroz2.pdf (visitado en agosto de 2013).

Ruffinelli, J. y Gaviria, V. 2004. Los márgenes al centro. Madrid: Casa de América-Turner.

Salinas, C. 2010. "Melodramas, identidades y modernidades en el cine latinoamericano actual: De Amores perros a Sábado". Aisthesis 48: 112-127. 
Santa Cruz, E. 2003. Las telenovelas puertas adentro. El discurso social de la telenovela chilena. Santiago: LOM. Santa Cruz, E. y Santa Cruz, L. 2005. Las escuelas de la identidad. Santiago: LOM-Arcis.

Sarlo, B. 2000. El imperio de los sentimientos. Buenos Aires: Norma.

Schwarzböck, S. 2009. Estudio crítico sobre Un oso rojo. Entrevista a Israel Adrián Caetano. Buenos Aires: Picnic.

Verardi, M. 2009. "Pizza, Birra, Faso: La ciudad y el margen". Bifurcaciones. Revista de Estudios Culturales Urbanos 9. En línea, disponible en: http://www. bifurcaciones.cl/009/pizzabirrafaso.htm (visitado en junio de 2013). 
